Kátia Reis de Souza 1

Brani Rozemberg 2

Adriana Kelly-Santos 1

Nancy Yasuda 1

Marta Sharapin 1

\section{O desenvolvimento compartilhado de impressos como estratégia de educação em saúde junto a trabalhadores de escolas da rede pública do Estado do Rio de Janeiro}

\author{
Shared development of printed material \\ as a health education strategy with public \\ school employees in Rio de Janeiro State
}

1 Centro de Estudos em Saúde do Trabalhador e Ecologia Humana, Escola Nacional de Saúde Pública, Fundação Oswaldo Cruz. Rua Leopoldo Bulhões 1480, Rio de Janeiro, $R J$ 21041-210, Brasil. katreis@ensp.fiocruz.br 2 Departamento de Epidemiologia e Vigilância em Saúde, Instituto de Pesquisa Clínica Evandro Chagas, Fundação Oswaldo Cruz. Av. Brasil 4365, Rio de Janeiro, $R J$ 21045-900, Brasil. braniroz@ipec.fiocruz.br

\begin{abstract}
This article describes the process and results of an experience with preparing a mural entitled A Day in the Life of the School Lunch Cook, conducted with public school employees in the State of Rio de Janeiro by a team of researchers and students from the Specialization Course in Workers' Health at the Center for Studies on Workers' Health of the National School of Public Health, Oswaldo Cruz Foundation, in partnership with the School Employees' Union. "Health workshops" based on participatory research were used to raise questions related to daily work by school lunch cooks and kitchen staff. Produced to share the results of workshops with other schools, the mural is highly meaningful in terms of the reality of a specific segment of public employees and is intended as food for thought. Based on the Paulo Freire popular education model, six meetings were held, following a script for the production of an educational leaflet including the selection of contents, the communications approach, and the style and format of the leaflet. The creativity in the images prepared by the school lunch employees based on actual experiences from their daily work made the workshops an enriching moment of exchange, in which the participants shared their ideas, values, beliefs, feelings, and life histories.
\end{abstract}

Key words Occupational Health; Broadsides; Health Education

Resumo Descrevem-se, aqui, o processo e o produto da experiência de elaboração do mural: Um Dia de Merendeira, realizada junto a trabalhadores de escolas da rede pública do Estado do Rio de Janeiro por equipe de pesquisadores e alunos do Curso de Especialização em Saúde do Trabalhador do Centro de Estudos da Saúde do Trabalhador e Ecologia Humana da Escola Nacional de Saúde Pública da Fundação Oswaldo Cruz, em parceria com o Sindicato dos Profissionais de Educação do Rio de Janeiro. A partir de "oficinas em saúde" pautadas na investigação participativa foram levantados problemas e questões relacionadas ao cotidiano de trabalho de merendeiras e serventes. Produzido para socializar nas escolas os resultados das oficinas, o mural é significativo da realidade daquele segmento específico e pretende informar e estimular a reflexão. Com base no referencial de educação popular de Paulo Freire, realizaram-se seis encontros seguindo um roteiro de trabalho para a construção do impresso educativo incluindo a seleção de conteúdos, escolha do gênero comunicativo, estilo e formato do impresso. A criatividade presente nas imagens elaboradas pelos trabalhadores a partir das situações vividas durante a realização de suas tarefas fez, das reuniões, um rico momento de troca, em que as participantes expuseram idéias, valores, crenças, afetos e histórias de vida.

Palavras-chave Saúde Ocupacional; Impressos Avulsos; Educação em Saúde 


\section{Introdução}

O presente artigo resume parte do trabalho desenvolvido na dissertação de mestrado da primeira autora (Souza, 2000), bem como se descreve um de seus desdobramentos, uma experiência de educação/comunicação popular que reúne, em parceria, o Sindicato dos Profissionais de Educação do Rio de Janeiro (SEPE-RJ) e o Centro de Estudos da Saúde do Trabalhador e Ecologia Humana, Escola Nacional de Saúde Pública, Fundação Oswaldo Cruz (CESTEH/ ENSP/FIOCRUZ, no âmbito de um programa mais abrangente (Brito et al., 2001). Delineamos os passos do desenvolvimento compartilhado de um material educativo, junto a merendeiras e serventes de escolas da rede pública, conduzido pelas autoras, que são professoras e alunas do Curso de Especialização em Saúde do Trabalhador do CESTEH, e que resultou em uma monografia (Santos et al., 2000).

Entre outras ações e pesquisas no âmbito do Programa de Formação em Saúde, Gênero e Trabalho nas Escolas (Brito et al., 2001), uma proposta de método educativo pautado sobre elementos da pedagogia popular e da investigação participativa vem se concretizando, desde 1998, através do que se convencionou chamar de "Oficinas em Saúde" (Souza, 2000). Para essa autora, a opção pelo estudo participativo resultaria num compromisso de formação dos trabalhadores, num processo de construção de autonomia do saber no campo da saúde e trabalho.

As oficinas envolveram trabalhadores e pesquisadores com base nos seguintes pressupostos: (1) o trabalhador é sujeito fundamental do processo de produção de conhecimento sobre a realidade dos problemas da saúde no trabalho; (2) a experiência no trabalho é o centro do processo educativo influindo na capacidade desses sujeitos de darem respostas, de forma organizada, às queixas de saúde; (3) considera-se o grupo um elemento facilitador onde estão dadas as condições coletivas para se operar a ação educativa; (4) a experiência e a cultura dos sujeitos envolvidos funcionam como ponto de partida para a produção de novos conhecimentos.

Ao longo das atividades das oficinas de saúde, foi possível identificar um conteúdo temático significativo para se produzir conhecimento sobre a relação saúde-trabalho dos profissionais de educação, destacando-se os seguintes tópicos: (1) a readaptação no trabalho e o sofrimento daqueles que adoeceram em decorrência do processo de trabalho; (2) a falsa separação entre trabalho manual e intelectual; (3) os conflitos de relação entre trabalhadores antigos e os novos; (4) as saídas para a defesa da saúde; (5) questões de gênero relacionadas ao trabalho; (6) acidentes de trabalho e uso de equipamentos de proteção individual; (7) insalubridade; e (8) a satisfação no trabalho gerada pela relação diária com as crianças. As categorias que figuraram como elementos centrais $\mathrm{e}$ facilitadores do método de trabalho das oficinas foram: diálogo, autonomia, solidariedade e participação (Souza, 2000).

Concentraram-se todos os esforços para que a discussão coletiva sobre transformações qualitativas da cultura de saúde predominante nos ambientes de trabalho pudesse potencializar novos espaços de discussão, dar visibilidade às condições de trabalho das serventes e merendeiras, bem como estender o debate para outros fóruns.

Entre os objetivos da formação de trabalhadores como sujeitos autônomos no que se refere ao conhecimento sobre a relação saúde-trabalho, está o de contribuir para uma emancipação política dos sujeitos envolvidos, favorecendo a luta sindical pela transformação das condições concretas no cotidiano de vida e trabalho dos participantes.

Como um dos produtos das oficinas, os trabalhadores, através do seu sindicato, sugeriram a elaboração de um material informativo/educativo que pudesse socializar os conteúdos problematizados nas oficinas em saúde.

Em uma perspectiva de articulação entre ensino e pesquisa, a equipe do CESTEH propõe, então, aos alunos do Curso de Especialização em Saúde do Trabalhador, a participação no processo de elaboração do material informativo/educativo. Teve início assim, no SEPERJ, o processo de produção, de forma participativa, de um impresso para uso em escolas da rede pública, analisado a seguir. A versão integral detalhada consta da monografia de especialização (Santos et al., 2000).

\section{Pressupostos metodológicos}

O processo de elaboração do impresso educativo sobre saúde no trabalho na escola teve por base o referencial de educação e comunicação popular de Freire (1977, 1983, 1988, 1997), de pesquisa participante de Thiollent (1986), os conceitos de investigação narrativa de Castillo (1993), diálogo em Freire (1983, 1988) e Habermas (1989, 1990), temas geradores em Freire (1983, 1988) e validação consensual em Oddone et al. (1986) e Castillo (1993).

A escolha por construir um material de forma conjunta entre trabalhadores, alunos e pes- 
quisadores favorece uma ação educativa, em que se buscam a troca de experiências e informações, relatos de histórias de vida, reflexão e problematização sobre os temas surgidos, assumindo suas experiências cotidianas de vida e de trabalho como fonte de conhecimento e de ação transformadora da realidade (Freire, 1988).

Neste processo, Freire (1988:69) destaca a importância da comunicação: "a educação é comunicação, é diálogo, na medida em que não é transferência de saber, mas um encontro de sujeitos interlocutores que buscam a significação dos significados".

Considerando o conceito de investigação narrativa na produção de impressos educativos (Castillo, 1993), em relação aos pólos de comunicação, não trabalhamos com posições fixas (investigador/investigado, pesquisador/pesquisado), e sim em uma relação de investigação narrativa mútua, onde foi possível aos sujeitos, no processo de grupo, no face a face, confirmarem ou refutarem os elementos que podiam ser úteis para o produto em elaboração.

Uma outra preocupação era de que o material - "o produto" - como meio de informação, fosse acessível e claro, significativo da realidade daquele segmento específico e que pudesse, além de informar, estimular a reflexão. Neste sentido, tomamos por base os temas geradores abordados durante as oficinas em saúde. O trabalho participativo da produção do impresso modificou-os e possibilitou o surgimento de novos temas.

Segundo Thiollent (1986:66), "na pesquisa ação, o processo de investigação está associado a uma capacidade de aprendizagem". Trata-se, neste caso, da aprendizagem de um novo conhecimento elaborado a partir da incorporação de diferentes visões de mundo e saberes, no esforço de fazer interagir o saber formal representado pelos pesquisadores e o saber informal dos trabalhadores. A metodologia participativa configura-se, assim, em um processo coletivo de aprendizagem através de práticas grupais (Gajardo, 1987).

Ao incorporarmos o saber dos trabalhadores, suas experiências e vivências, privilegiando-as, estamos buscando, dentro do campo de investigação da saúde do trabalhador, uma nova relação no processo de conhecimento, produzindo autonomia e transformações das condições que geram prejuízos à saúde do trabalhador (Oddone et al., 1986).

Destacamos um dos conceitos que utilizamos nesse processo de construção do conhecimento que é o da validação consensual, elaborada a partir do confronto das experiências de cada trabalhador (Oddone et al., 1986). Desta maneira, amplia-se o conhecimento a partir das observações de cada sujeito envolvido (Souza, 2000).

Um outro conceito fundamental utilizado aqui e que possibilita a ação educativa é o do diálogo. Para que este ocorra de uma maneira em que todos os envolvidos no processo tenham as mesmas oportunidades de escolhas e realizações da fala, Habermas propõe quatro subpostulados conhecidos como fala ideal (Siebeneichler, 1989):

1) Postulado da igualdade comunicativa: todos com igual chance de usar os atos da fala.

2) Postulado da igualdade da fala: todos com igual chance de proceder interpretações, fazer asserções, recomendações, explicações e justificativas, bem como de problematizar pretensões de validade.

3) Postulado da veracidade e sinceridade: todos com igual chance de expressar idéias, sentimentos e intenções pessoais.

4) Postulado das correções de normas: todos com igual chance de empregar atos de fala regulativos, isto é, de mandar, de permitir, de proibir e de fazer e retirar promessas.

Tais postulados, que descrevem uma situação de comunicação de fala ideal, nortearam nossa reflexão na condução desse processo de construção partilhada de conhecimento, de modo a garantir a participação democrática dos sujeitos envolvidos.

\section{Procedimentos metodológicos}

A partir dos referenciais metodológicos de investigação e de trabalho participativo, e levando em consideração o prazo para conclusão da monografia do Curso de Especialização, planejamos a realização de cinco reuniões denominadas cenas, com os trabalhadores, entre setembro e novembro de 2000, as quais chamamos de cenas. Paralelamente, ocorreram reuniões regulares de orientação com as alunas, planejamento e análise das cenas, como preparação do trabalho da monografia.

Quanto ao local onde as reuniões aconteceram, o qual denominamos cenário, trabalhamos na sede da Regional II do SEPE-RJ, localizado em um prédio comercial de uma das principais avenidas do bairro de Madureira, Zona Norte do Rio de Janeiro.

Quanto aos atores do processo, além das autoras do presente artigo, daqui para frente referidas indistintamente como pesquisadoras, contamos com merendeiras, serventes e professores, a maior parte deles sindicalista. Todos vinham para as reuniões após a jornada de tra- 
balho, chegavam cansados e atrasados, mas dispostos para a tarefa.

O passo a passo do processo de produção de impressos

Como roteiro inicial para cada encontro, utilizamos as etapas do processo de comunicação social, porém adaptadas para a forma de perguntas e em uma linguagem do senso comum (Rozemberg, 1998), de modo a nortear as decisões do grupo sobre o material a ser produzido:

1) Qual o nosso problema/tema? Momento de investigação e definição do assunto e recorte temático a ser trabalhado no material.

2) O que queremos conseguir? Definição da intenção dos produtores da mensagem e dos resultados esperados, considerando-se contexto, objetivos e interesses por atender.

3) A quem queremos chegar? Segmentação da audiência, ou seja, "a quem" a mensagem será dirigida, de modo a conferir direcionalidade e adequação aos públicos.

4) O que queremos dizer-lhes? Seleção dos conteúdos que comporão a mensagem.

5) Como queremos lhes dizer? Transformação dos conteúdos selecionados em mensagens, definindo-se as estratégias comunicativas: gênero (drama, comédia etc.), estilo (formal/informal, linguagem direta/indireta), e formato (vídeos, folhetos etc.).

6) Façamos! É a etapa da produção do material, ou seja, sua execução.

7) Fizemos bem? Etapa da avaliação tanto do processo de produção quanto do produto.

8) Divulgação? Planejamento da circulação, custo, acesso por parte do público, tiragem.

Na monografia das alunas da especialização do ano de 2000 (Santos et al., 2000) descreve-se a experiência do trabalho até a etapa de construção coletiva da mensagem e produção efetiva do impresso.

O planejamento das cenas buscou responder a todas as etapas de trabalho, ainda que muitas tenham ocorrido de maneira concomitante. Por estarmos trabalhando em uma lógica participativa, incluímos ainda um ponto: o contrato com o sindicato e a definição do grupo de "produtores da mensagem". Assim, nossos objetivos para cada cena foram: Cena I: Estabelecimento do contrato - validação da proposta de produção de impresso; Cena II: Definição dos participantes e levantamento dos temas a serem trabalhados; Cena III: Definição dos temas a serem trabalhados e a quem se dirigiria o impresso; Cena IV: Negociação dos conteúdos e elaboração da mensagem. Produ- ção; Cena V: Definição de estratégias para apresentar os conteúdos no impresso. Produção.

\section{Resultados}

Cena I - A construção da proposta de produção dos impressos educativos

De início, uma das pesquisadoras apresentou a história do projeto integrado de pesquisa em andamento em parceria com o SEPE-RJ, já que algumas pessoas no grupo não a conheciam. Os trabalhadores que haviam participado do processo ajudaram no relato, contando como foram modificando sua visão acerca das questões sobre saúde/trabalho no decorrer da pesquisa:

“... Eles (os pesquisadores) deram livros para a gente ler...”; “... Começamos a perceber o que as pessoas não percebiam (os riscos no trabalho)..."; "As pessoas tem que trabalhar para lutar pelo seu dia a dia e acabam adoecendo..."; "Começamos a questionar que valor é esse, dado à saúde...”.

Na seqüência, foram questionados o financiamento do material, sua distribuição e tiragem previstas, indicando a expectativa de que tudo isso já viesse definido a priori, por uma instância superior. Esclarecemos a eles que tudo seria discutido ali, no grupo, e que até mesmo a realização ou não do trabalho deveria ser definida naquele encontro, questionando se ainda havia interesse do Sepe na produção do material educativo.

Diante da resposta afirmativa, o grupo passa a discutir os pontos do contrato. Definiu-se, então, que seriam realizados cinco encontros semanais, com duas horas de duração, em função da disponibilidade dos presentes.

Com relação aos limites de exclusão/inclusão de participantes no grupo de elaboração do material, definiu-se que o convite seria destinado a todos os interessados e que a definição das pessoas deveria acontecer na reunião do "Coletivo" do SEPE-RJ, o que ocorreria na semana subseqüente. Surgiram sugestões de "resgatar o grupo que já participou das oficinas", o que foi aceito por consenso.

A partir da fala de uma professora, definiuse que o segmento ao qual o material deveria ser dirigido seria o das merendeiras e serventes: "como forma de concretizar o trabalho que já foi realizado até o momento (com elas)".

Um professor inicia a discussão sobre a forma que o impresso poderia ter, sugerindo que o material fosse "interativo, no qual o públicoalvo pudesse reconhecer sua própria condição 
de saúde" Sua sugestão incluía um "teste" utilizando escalas para que o público se enquadrasse em relação às suas condições de adoecimento no trabalho. O professor acrescentou ainda: "podemos colocar um anexo no impresso, onde a pessoa responda qual é o caso dela, $e$ aí você diz o que ela deve fazer".

Percebe-se, nessa sugestão, a tendência de reprodução de um modo de entender e lidar com o outro no processo de comunicação, considerando-o como sujeito passivo, receptor de mensagens, buscando enquadrá-lo oferecendo soluções prontas. Fica explícita também a crença de que seria necessário "sensibilizálo", como se ele fosse incapaz de perceber e de lidar, ao seu modo, com seu problema e sofrimento. Discutimos no grupo esse tipo de visão, ressaltando o valor de nossa interação no processo de elaboração do material educativo, e não apenas o valor do impresso como produto acabado. Neste sentido, não caberia no impresso, simplesmente "dizer ao outro o que deve fazer”. Uma pesquisadora acrescenta ainda que o que se pretende é que, a partir do conhecimento individual interagindo com o coletivo, seja possível um novo conhecimento sobre as relações entre saúde e trabalho.

O grupo elegeu as questões do reconhecimento e da valorização (inclusive financeira) do trabalho das merendeiras e serventes e da dignidade nas relações de trabalho como pontos geradores de saúde no trabalho, e fundamentais na mensagem do impresso.

Várias outras sugestões de conteúdos para o impresso surgiram para serem trabalhadas nos encontros seguintes, tais como: "A dor não tem cor, não aparece, não é vista"; "Secretaria da Educação nos valoriza (merendeiras) na palavra, mas não na prática”; "As boas relações (na escola) geram saúde, principalmente saúde mental"; "Se não for humilhada, mesmo doente, (a pessoa) pode trabalhar..."

\section{Cena II - No coletivo de trabalhadores: definição do grupo de elaboração do impresso}

Realizamos um levantamento dos impressos produzidos pelo SEPE-RJ, como forma de aproximação da cultura de comunicação do sindicato com a base de trabalhadores.

Apesar de divulgada pelos sindicalistas em algumas escolas, a reunião contou apenas com a presença dos próprios sindicalistas. Vale ressaltar que este encontro é a reunião do coletivo da classe, que ocorre uma vez por mês, funcionando como instância deliberativa. A fraca participação da categoria evidencia o processo atual de esvaziamento e de fragilização pelo qual passa o movimento sindical.

Os participantes buscaram, então, entender os motivos pelos quais os trabalhadores não estavam presentes, relatando vários impeditivos:

"Estamos com dificuldade de mobilizar as pessoas por questões financeiras (sem telefone, sem repasse da contribuição sindical por parte do Governo do Estado) e muitos trabalhadores não tem dinheiro para transporte".

Outro motivo apontado seria a frustração dos trabalhadores com atividades realizados anteriormente: "Eu participei à beça daqueles encontros e não deu em nada".

Segundo a representante sindical, qualquer trabalho que se faça gera nos participantes a expectativa de um aumento de remuneração. Isso, muitas vezes, reduz a adesão a novos eventos ou programas promovidos pelo sindicato, uma vez que a maioria das propostas está orientada para a luta pela melhoria de condições de trabalho, e não somente para reajuste salarial.

Considerando-se que as pessoas ali presentes eram suficientes e justificavam aquele encontro, teve início a tarefa proposta para a nossa cena II, a saber: definir os participantes do processo de elaboração do impresso. Decidiuse, então, que as reuniões transcorreriam abertas com o número de trabalhadores que estivessem presentes. Tudo o que fosse definido nas reuniões seria repassado aos participantes das reuniões seguintes.

\section{Cena III - Construindo o produto a partir} da realidade: a definição do formato e a validação do conteúdo temático das oficinas de saúde.

Com o objetivo de levantar o conteúdo a ser trabalhado no impresso, inicialmente foram discutidos vários fatores que levam ao adoecimento no trabalho: "Tenho problemas de saúde depois que fui trabalhar na escola, problemas de coluna, varizes..." (merendeira); "Ninguém é obrigado a carregar a escola nas costas..." (merendeira); "Não vim reclamar de salários, pois quando entrei sabia que era baixo... vim reclamar sobre as condições de trabalho..." (professora).

De modo a sistematizar a eleição de conteúdos e a validação de sua possível aplicação no impresso, uma das pesquisadoras apresentou ao grupo uma síntese de temas levantados nas oficinas de saúde, já descritos na introdução deste artigo.

O debate foi enriquecido por uma participante que se integrou ao grupo nesta cena, cu- 
ja experiência e visão da temática contrastavam com as dos demais trabalhadores: "A escola também tem saúde, minha escola é muito boa.."; "Professores, diretora e merendeiras não tem problemas, o relacionamento é bom"; "A diretora é severa, tem que ser. Mas é muito amiga, sempre pronta para ajudar..."; "Sou merendeira, prefiro trabalhar sozinha e deixar as duas que são novatas juntas..."; "A saúde você tem.. A queixa é pelo fato de pegar peso, cortar carne congelada... mas isso não é responsabilidade da direção".

Estão implícitas neste discurso a naturalização da hierarquia das relações, a banalização dos riscos e dos fatores que geram agravos à saúde e a reafirmação dos ethos profissional de merendeira, estratégias defensivas encontradas pela trabalhadora para lidar com as condições de trabalho. Tais estratégias, segundo Dejours (1994:127), "resultam dos conflitos entre organização do trabalho e funcionamento psíquico".

\section{- A escolha do formato para o impresso}

A idéia de um mural tornou-se a opção escolhida pelo grupo, por tratar-se de formato que, além de muito utilizado no universo escolar, seria mais acessível à merendeira, pois pode ser afixado, facilitando a comunicação visual e o acesso por parte de um público com pouca familiaridade com a linguagem escrita. Por limitações de tempo, agendamos para o encontro seguinte o início da produção do mural.

\section{Cena IV - Organização e detalhamento} dos temas geradores

Neste encontro ressaltamos que o eixo organizador dos conteúdos levantados seria a Saúde, bem como sugerimos que o grupo discutisse o que seria saúde no trabalho na escola.

Uma servente, que participava do grupo pela primeira vez, inicia contando sua história: "Eu não era doente quando comecei a trabalhar. É muita tensão, hoje tenho labirintite, escoliose, angina (...) já passei cinco dias chorando, de nervoso".

Segundo ela, sua saúde ficou mais prejudicada pelo medo e pela falta de informações: "Ninguém me falou nada sobre licença (médica), eu não sabia como fazer (...) Eu estava grávida e tinha tanto medo de ser mandada embora, que o serviço que não fazia na minha casa, fazia na escola. Mandavam fazer, eu fazia".

A fala dessa trabalhadora evidencia o isolamento vivido por ela e outros, tanto na vivência dos problemas quanto na busca de soluções. Coloca-se aqui a importância do diálogo, da troca de conhecimentos como fator gerador de saúde no trabalho, além de possibilitar a luta pelos direitos do trabalhador. Com isso, o grupo refletiu sobre o quanto os posicionamentos, individuais ou coletivos, pela garantia dos próprios direitos são momentos de autovalorização e de afirmação das próprias possibilidades e capacidades: "Agora que sou mais esperta, me sinto mais saudável. Ser esperta é estar atenta aos direitos. Hoje em dia eu procuro os meus direitos"; "Para manter a saúde, tem que falar..."; "Quando vou em algum lugar e aprendo alguma coisa, logo passo para as colegas..."; "Na greve, a auto-estima fica elevada, a gente encontra os pares...".

O grupo retomou a tarefa de organização dos conteúdos e definiu que os temas levantados seriam divididos em dois eixos principais, "Isto é Saúde" e "Isto não é Saúde".

$\mathrm{O}$ primeiro eixo dizia respeito às práticas $\mathrm{e}$ estratégias relatadas pelas merendeiras e serventes que favoreciam a saúde no trabalho (a satisfação no relacionamento com as crianças), ao passo que o segundo apontaria para os problemas e pressões vividas no ambiente de trabalho e seus determinantes (sobrecarga de trabalho, isolamento, entre outros).

Já os temas "Acidente de Trabalho", "Uso de Equipamentos de Proteção Individual” e "Insalubridade" foram excluídos, sob pena de aumentar a densidade de informações, comprometendo a qualidade do produto final. Poderiam ser apenas citados no final como chamadas de assuntos a discutir mais profundamente em outro momento.

Cena V - A dinâmica da criação: a transformação dos conteúdos em mensagens

O objetivo deste encontro era definir como os conteúdos levantados e organizados previamente em forma de texto poderiam ser colocados no mural, tanto em relação ao estilo e formas de linguagem a serem adotados, como em relação ao uso de imagens. E ainda, o que receberia destaque, e como distribuir os conteúdos na área do mural.

Para facilitar a visualização desta construção, as pesquisadoras levaram material (papel pardo, pincéis atômicos) para que o grupo pudesse esboçar diferentes versões de um cartaz que contivesse tudo o que fosse definido como mensagem para o mural definitivo.

Observou-se, nesta cena, um dinamismo que perpassa todo o processo de construção do conhecimento compartilhado entre pesquisadores trabalhadores. 
Uma das pesquisadoras iniciou a leitura do material organizado e, nas discussões, algumas questões começaram a surgir: o tipo de discurso que seria utilizado (direto ou indireto), o que seria destacado graficamente, como evitar a densidade de informações no mural (palavras e imagens em excesso para a área disponível) e o que poderia levar a um comprometimento da apreensão das mensagens.

A idéia inicial era fazer do mural uma espécie de chamariz, algo visualmente agradável que chamasse a atenção dos trabalhadores para o debate que ele continha.

Logo durante a leitura das primeiras frases, $o$ grupo fez a opção pelo discurso direto a fim de favorecer a identificação e a formação de um vínculo com o público do mural. Um exemplo dessa transformação de estilo diz respeito à seguinte frase: "Este trabalho baseia-se numa pesquisa sobre as condições de trabalho de merendeiras e serventes...", que passou a ser: “Ouvimos muitas merendeiras e serventes...”. Neste momento, o grupo também decidiu um estilo informal para tratar dos temas geradores no mural.

Retomou-se a leitura dos textos e, ao mesmo tempo, uma das representantes do sindicato tomou a iniciativa e começou a escrever, no cartaz, as frases escolhidas pelo grupo. Neste processo, ficou claro que algumas frases estavam muito extensas, o que poderia gerar dificuldades de leitura e de captação da atenção do leitor. Deu-se início, então, a um processo de redução/ampliação de conteúdos, caracterizando um movimento de "fluxo e refluxo", próprio das metodologias participativas.

Uma outra preocupação presente na discussão girou em torno de palavras/expressões que pudessem ter um duplo sentido, soar artificiais, denegrir ou ferir crenças e valores, ou gerar discriminação. Um bom exemplo disso foi a discussão sobre o uso da expressão: "Fique esperta!" que apareceria com certo destaque, como forma de instigar os trabalhadores a pensar nas relações entre as queixas de saúde e as condições nas quais desenvolviam suas tarefas. A expressão, no entanto, acabou excluída do mural, por despertar no grupo a preocupação com seu duplo sentido na cultura brasileira. Esperteza é muitas vezes sinônimo de oportunismo e malandragem. Além disso, uma merendeira lembrou que a expressão também poderia ser ofensiva, se associada à idéia de que os trabalhadores não estivessem desempenhando bem suas tarefas: "Vão pensar que elas estão se encostando, fazendo corpo mole, que estamos dizendo que são lerdas...”.

O título escolhido para o mural foi: "Mural da Saúde do Trabalhador”. Ao final da reunião, ainda faltava organizar todas as mensagens no espaço do mural. Afirmando seu engajamento na finalização desta tarefa, o grupo acertou realizar mais uma reunião.

\section{Cena VI - A transformação \\ de conteúdos em mensagens}

A reunião teve início com a leitura, por uma das trabalhadoras, do cartaz produzido na cena anterior. A partir da proposta de uma das pesquisadoras para que tentássemos trabalhar com imagens, esta cena foi marcada pela tentativa de se criar imagens das merendeiras e serventes que estivessem associadas aos temas selecionados na Cena IV: "Como podemos representar as merendeiras e serventes sobrecarregadas?” As respostas vieram em seguida: “um robô?", "vários braços?”, "uma mulher carregando uma escola nas costas?", "uma mulher com vários braços fazendo mil coisas”. Essa última imagem foi logo aceita por todos e reforçada pela fala de uma professora : “...lá na escola, a diretora diz que todos os funcionários são multi-uso". Essa mesma professora lembrou ao grupo as reclamações sobre o pouco tempo que serventes e merendeiras dispõem para realizar as tarefas. Uma das merendeiras acrescentou: "quando acaba o lanche, tá na hora de servir o almoço. Quando termina a merenda, ainda tem de limpar todo o refeitório".

Uma das pesquisadoras sugeriu a utilização de tiras (como quadrinhos) de gibi para montar uma estória, mostrando como seria um dia na vida de uma merendeira.

Outra pesquisadora começa a esboçar no cartaz as imagens associadas às condições adversas enfrentadas pelas trabalhadoras: "um relógio bem grande” (para expressar a pressão do tempo); "uma fila com crianças barulhentas e a merendeira de vários braços, com duas mãos na cabeça, tapando os ouvidos, com outra mão servindo comida, e outra ainda segurando utensílios" (para expressar a exposição a ruídos e o excesso de trabalho); "uma merendeira com o machado para cortar o frango congelado e ao fundo o calor das panelas" (para expressar o esforço e a exposição ao choque de temperaturas); "Uma merendeira no final da jornada de trabalho caída, "morta" de cansada e balões flutuando em volta dela, cada um contendo uma das queixas de saúde referidas" (para expressar além do cansaço sua preocupação e vivência de doenças relacionadas ao trabalho).

A criatividade presente nas imagens elaboradas pelos próprios trabalhadores a partir das situações vividas durante a realização de suas 
tarefas fez, desse momento, um momento de troca extremamente rico.

Uma representante do sindicato lembra a ênfase dada, até aquele ponto, às atividades das merendeiras em relação as atividades das serventes. É, então, proposta e aceita a idéia de se trabalhar com mais uma tira, para ilustrar as situações vividas pelas serventes. As imagens relativas às serventes esboçadas no cartaz, tais como: "Uma servente limpando pichações no alto de uma parede, no banheiro, sem botas ou luvas" (movimentos repetitivos e a falta de equipamentos de proteção individual); "Os produtos de limpeza utilizados sendo representados com figuras de caveiras" (manipulação de produtos cujo uso causa reações alérgicas, entre outros problemas).

Ao final, constatamos que os conteúdos relacionados à promoção em saúde no trabalho haviam sido abordados em forma de texto, ao passo que as dificuldades, os problemas de saúde foram representados através de imagens, com humor. Ainda que não intencional, tal estratégia parece ter facilitado a abordagem das temáticas mais delicadas, associadas ao sofrimento físico e psíquico (Figura 1 - reprodução do mural).

\section{Considerações finais}

Destacamos de início o quanto a proposta participativa, por sua dinâmica inerente, exige maleabilidade na execução do planejamento sem que se perca o objetivo da tarefa. Assim, conforme as definições foram surgindo nas discussões, o grupo ditava a trajetória do processo e então, o que havia sido planejado para a Cena II, por exemplo, foi adiado para a Cena III sem que isso, contudo, comprometesse o conjunto do trabalho.

Essa maleabilidade aparece também no contrato com relação à composição do grupo que, na prática, foi "flutuante". A continuidade do trabalho foi garantida pela definição clara dos objetivos de cada encontro, assumida por todo o grupo. Nesse sentido, a presença de novos participantes sempre enriqueceu as discussões, por trazer novos pontos de vista e explicitar contradições, o que possibilitou ao grupo integrar as diferenças na construção de um conhecimento compartilhado.

Outro aspecto refere-se à expectativa inicial de alguns participantes por relações hierarquizadas e definições prontas, trazidas de instâncias superiores, refletindo o paradigma incorporado da "transmissão de conhecimento", no qual os sujeitos assumem papéis fixos - o " $d a$ - quele que sabe, que ensina" (o emissor) e o "daquele que não sabe" (o receptor), em uma lógica de sujeitos "passivos" que formariam um "público-alvo".

Castillo (1993:2) afirma que qualquer material impresso traz implícito sempre "un modo de calificar al otro y de situarse en el proceso". Assim, no modelo comunicacional adotado, houve espaço para modos distintos de situarse no processo, que produziram, ao final, um nova interação subjetiva entre os envolvidos.

Tivemos, de um lado, os pesquisadores representando o saber formal, fundamentados na concepção de um sujeito que é capaz de aprender e de utilizar suas experiências como referencial para transformação da realidade, porém, sem a vivência concreta do trabalho como merendeiras ou serventes. E de outro, os trabalhadores com o saber fazer, isto é, o saber construído na prática do seu trabalho e nas relações sociais a que estão submetidos. Segundo Gramsci (1972, apud Macciochi, 1980:216): “O elemento popular sente, mas nem sempre compreende ou sabe; o elemento intelectual sabe, mas nem sempre compreende ou, sobretudo, sente".

Os trabalhadores que integraram este estudo apresentavam uma visão que, muitas vezes, denunciava uma concepção de sujeito dependente, centrado no individualismo, sem possibilidade de dialogar e estagnado em papéis estabelecidos pelo grupo no qual está inserido. Assim, buscamos um espaço de aprendizagem coletiva, favorecendo a ruptura de modelos como esse, e o exercício da autonomia criativa.

Segundo Souza (2000:29), "esse processo de interação entre os dois saberes possui um valor ético, que é o respeito ao conhecimento obtido por cada pessoa no seu trabalho e na vida. Seja ele trabalhador ou pesquisador, produz novos lugares: trabalhador que investiga; pesquisador que é investigado". O importante foi a aliança estabelecida pela meta comum de reconhecimento crítico e de busca de caminhos para as transformações necessárias para a promoção da saúde, dentro dos limites possíveis, nos ambientes de trabalho.

Merece atenção a dificuldade de se trabalhar o tema da saúde. Mesmo tendo sido definido como tema central (início da Cena IV), o eixo do debate rapidamente tomou o caminho da "doença". Em parte a dificuldade em discutir saúde se relaciona ao grau de idealismo e abstração a ela associados nas sociedades contemporâneas: "completo bem-estar físico, mental e social", ao passo que as manifestações muito concretas dos "entraves à saúde" são tangíveis. Como resultado, o trabalho participativo (Figura1) gerou referências a fatores de promo- 


\section{Mural de Saúde do Traballhador VIVER COM SAÚDE NA ESCOLA É POSSÍVEl?}

ESCUTAMOS MUITAS MERENDEIRAS E SERVENTES, E QUANTAS IDEIAS SAUDÁVEIS, MAS TAMBÉM MODOS DE VIVER E DEFENDER SUA SAÚDE!
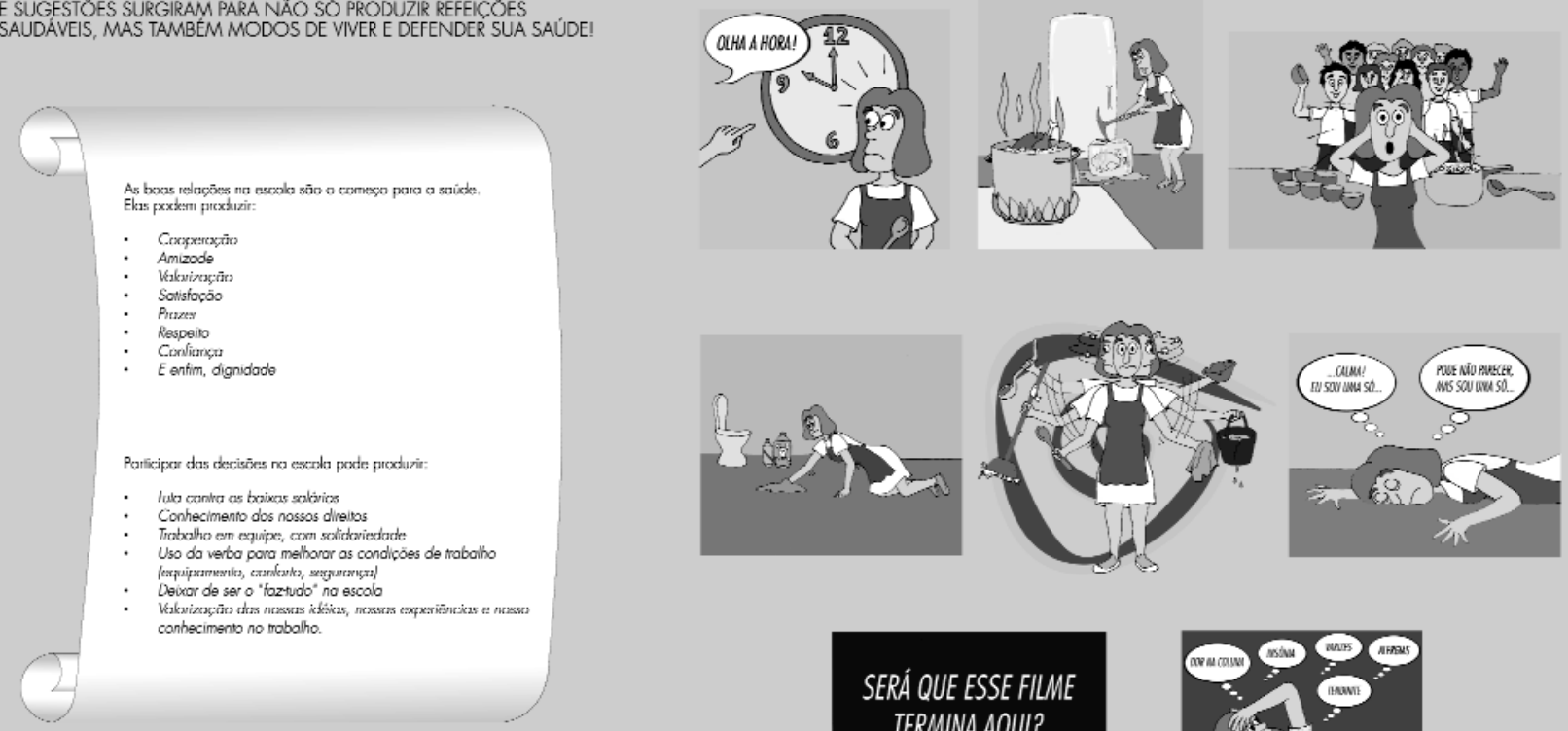

TANTOS ASSUNTOS AINDA PARA FALAR

- os acidentes de tRabalHO: QUEMAdURAS, QUeDAS, TRAUMAS

- A READAPTACAAO DO TRABALHO TEM SENTIDO?

A INSAIUBRIDADF COMPENSA?

OBSERVE: A SAÚDE TEM UMA UNGUAGEM PROPRIA QUE TODOS NOS SENTMOS E DEVEMOS COMPARTILHAR. AFINAL, OS PROBLEMAS DE SAÚDE SÃO PROBLEMAS QUE AFETAM A TODOS, UNS MENOS, OUTROS MAIS, MAS A TODOS!

VAMOS PENSAR SOBRE ISTOI

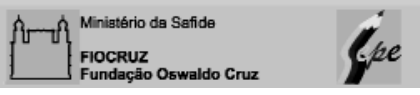


ção da saúde no trabalho, apenas em texto, enquanto o foco principal e as ilustrações privilegiaram a visibilidade dos entraves à saúde vividos no trabalho. Como vimos, o uso de caricaturas e imagens acabou também suavizando a abordagem dos temas delicados, ligados ao sofrimento no trabalho.

Finalmente, as reuniões permitiram o exercício do que Boutet (1993) denomina "atividade de linguagem”: um processo (...) cognitivo, psíquico e afetivo, onde a enunciação engaja os sujeitos como indivíduos singulares e complexos que exprimem ao mesmo tempo conhecimentos, saberes, emoções e afetos.

\section{Referências}

BOUTET, J., 1993. Atividade de linguagem e atividade de trabalho. Educación Permanente, 116:108-117.

BRITO, J.; BARROS, M. E.; NEVES, M. \& ATHAYDE, M. (org.), 2001. Trabalhar na Escola? Só Inventando o Prazer. Rio de Janeiro: Edições IPUB.

CASTILLO, D. P., 1993. Comunicación Rural por Impresos: Entre la Ilusión y el Despilfarro. Mendonza: Radio Nederland Training Center. (mimeo.)

DEJOURS, C., 1994. Psicodinâmica do Trabalho. São Paulo: Atlas.

FREIRE, P., 1977. Extensão ou Comunicação? Rio de Janeiro: Paz e Terra.

FREIRE, P., 1983. Educação como Prática de Liberdade. Rio de Janeiro: Paz e Terra.

FREIRE, P., 1988. Pedagogia do Oprimido. Rio de Janeiro: Paz e Terra.

FREIRE, P., 1997. Pedagogia da Autonomia: Saberes Necessários à Prática Educativa. São Paulo: Paz e Terra.

GAJARDO, M., 1987. Pesquisa participante: Propostas e projetos. In: Repensando a Pesquisa Participante (C. R. Brandão, org.), pp. 15-50, São Paulo: Brasiliense.

HABERMAS, J., 1989. Consciência Moral e Agir Comunicativo. Rio de Janeiro: Tempo Brasileiro.

HABERMAS, J., 1990. O Discurso Filosófico da Modernidade. Lisboa: Dom Quixote.

MACCIOCHI, M. A., 1980. A Favor de Gramsci. Rio de Janeiro: Paz e Terra.
A experiência ressaltou a importância do Espaço da Fala, onde os trabalhadores e pesquisadores puderam se expor, de maneira a superar seus preconceitos e construir coletivamente um novo sentido para suas experiências. Ou seja, foi possível não apenas falar sobre saúde/doença mas, sobretudo, produzir um momento saudável, de vivência participativa. Recomendam-se, deste modo, as iniciativas de produção de materiais educativos incorporando o trabalhador como sujeito do conhecimento, e não apenas como "público-alvo" de produtos construídos fora da experiência dos grupos.

ODONNE, I.; MARRI, G.; GLORIAS, S.; BRITANTE, G. \& CHIATELLA, M., 1986. Ambiente de Trabalho: A Luta dos Trabalhadores pela Saúde. São Paulo: Editora Hucitec.

ROZEMBERG, B., 1998. Tópicos em Comunicação em Saúde. Rio de Janeiro: Escola Nacional de Saúde Pública, Fundação Oswaldo Cruz. (mimeo.)

SANTOS, A. K.; YASUDA, N.; SHARAPIN, M.; SOUZA, K. R. \& ROZEMBERG, B., 2000. A Comunicação em Saúde por Impressos junto a Serventes e Merendeiras: Processo e Produto. Monografia de Especialização, Rio de Janeiro: Escola Nacional de Saúde Pública, Fundação Oswaldo Cruz.

SIEBENEICHLER, F. B., 1989. Jurgen Habermas: Razão Comunicativa e Emancipação. Rio de Janeiro: Tempo Brasileiro.

SOUZA, K. R., 2000. Para uma Pedagogia da Saúde no Trabalho: Elementos para um Processo Educativo em Saúde do Trabalhador. Dissertação de Mestrado, Rio de Janeiro: Núcleo de Tecnologia Educacional para a Saúde, Universidade Federal do Rio de Janeiro.

THIOLlENT, M., 1986. Metodologia da PesquisaAção. São Paulo: Cortez Editora.

Recebido em 20 de dezembro de 2001

Versão final reapresentada em 6 de agosto de 2002

Aprovado em 22 de novembro de 2002 